OPEN ACCESS

Edited by:

Xiao-Jun Ji,

Nanjing Tech University, China

Reviewed by:

Xiao-Man Sun,

Nanjing Normal University, China

Hu-Hu Liu,

Hunan Agricultural University, China

*Correspondence:

Zhi-Qiang Liu

microliu@zjut.edu.cn

Specialty section:

This article was submitted to

Industrial Biotechnology,

a section of the journal

Frontiers in Bioengineering and

Biotechnology

Received: 26 October 2020 Accepted: 15 December 2020 Published: 01 February 2021

Citation:

Huang $K$, Zhang B, Chen Y, Liu Z-Q and Zheng $Y-G$ (2021) Comparative

Transcriptome Analysis of

Streptomyces nodosus Mutant With a

High-Yield Amphotericin B.

Front. Bioeng. Biotechnol. 8:621431.

doi: 10.3389/fbioe.2020.621431

\section{Comparative Transcriptome Analysis of Streptomyces nodosus Mutant With a High-Yield Amphotericin B}

\author{
Kai Huang ${ }^{1,2}$, Bo Zhang ${ }^{1,2}$, Yu Chen ${ }^{1,2}$, Zhi-Qiang Liu ${ }^{1,2 *}$ and Yu-Guo Zheng ${ }^{1,2}$ \\ ${ }^{1}$ The National and Local Joint Engineering Research Center for Biomanufacturing of Chiral Chemicals, Zhejiang University of \\ Technology, Hangzhou, China, ${ }^{2}$ Key Laboratory of Bioorganic Synthesis of Zhejiang Province, College of Biotechnology and \\ Bioengineering, Zhejiang University of Technology, Hangzhou, China
}

Antibiotics play an important role in human health. Most antibiotics are derived from microbial secondary metabolites. Amphotericin is a polyene macrolide antibiotic synthesized by Streptomyces nodosus. S. nodosus ZJB2016050 with high-yield amphotericin B (AmB) was obtained by traditional mutagenesis using S. nodosus ATCC14899 as the original strain. The differences in the characterization of the two strains were found in color, mycelium morphology, and AmB yield. Subsequent comparative transcriptome explained the yield differences between the two strains. Pathways including the carbohydrate metabolic pathway and the secondary product synthesis pathway were targeted. The upregulation of glucokinase, phosphoglycerate mutase, and pyruvate dehydrogenase accelerates the consumption of glucose and has great effects on the accumulation of precursors. One of the competitive secondary metabolites of the polyketone synthetase (PKS) II type sapromomycin analog synthesis gene cluster was downregulated, which competes for malonyl-CoA. Five PKS modules (except for the first module amphA) of the amphotericin synthetic gene cluster in the high-yielding strain were downregulated, which resulted in the total amphotericin A (AmA) and AmB of S. nodosus ZJB2016050 being less than that of the wild-type S. nodosus ATCC14899. Combined with gene differential expression in the pentose phosphate pathway and the reaction mechanism of the ER5 domain, the reason that $S$. nodosus ZJB2016050 preferred to synthesize AmB was probably related to intracellular reduction.

Keywords: Streptomyces nodosus, amphotericin, comparative transcriptome, mutagenesis, metabolic pathway

\section{HIGHLIGHTS}

- A high-throughput screening method with inhibition zone was constructed to screen amphotericin B high-yield Streptomyces nodosus.

- S. nodosus ZJB2016050 was obtained by UV and NTG mutagenesis. The yield of AmB was 5.9 $\mathrm{g} / \mathrm{L}$, and the by-product AmA was $0.6 \mathrm{~g} / \mathrm{L}$ in flasks.

- Through comparative transcriptome analysis, the reasons for the high yield of amphotericin B in S. nodosus ZJB2016050 were analyzed. The expression difference in the glycolysis pathway, competing secondary metabolites synthetic gene clusters, and the amphotericin synthetic gene cluster are considered to be the reasons for the difference in the AmB yield of the two strains.

- Analysis of the transcriptome showed differences in the transcription levels of S. nodosus ZJB2016050 and the wild-type S. nodosus ATCC14899. This work provides theoretical support for the subsequent genetic modification of S. nodosus ZJB2016050. 


\section{INTRODUCTION}

Fungal infection is a major global problem with 1.6 million people dead per year (McAlister and Shapiro, 2019). As human immunodeficiency becomes more common, fungal infection is becoming more prevalent and dangerous. Currently, the most effective way to target fungal infections is to use antibiotics. However, the current situation is not optimistic with the increasing antibiotics resistance of pathogenic microorganisms and the lack of novel antibiotic discovery (Amara et al., 2018). The development of new antibiotics and the research of existing antibiotics are still urgent (Li and Vederas, 2009).

Streptomyces species belong to actinomycetes, and more than two-thirds of the antibiotics have been discovered in this genus (Hopwood, 2007). The classes of antifungal agents used for fungal infection include azoles (posaconazole and isavuconazole), polyenes (amphotericin and its lipid formulations), and echinocandins (caspofungin and micafungin) (Nami et al., 2019). Amphotericin B is produced by Streptomyces nodosus, which belongs to polyene macrolide antibiotic and is widely used in clinical treatment with good effect (AbuSalah, 1996; Hartsel and Bolard, 1996). AmB is effective against emerging pathogens such as Candida auris, a kind of yeast that is multidrug-resistant, is highly infectious, and has high mortality (Escandón et al., 2019; Forsberg et al., 2019). Besides, novel application study of $\mathrm{AmB}$ is also popular. The derivative liposomal $\mathrm{AmB}$ has the same antibacterial effect but lower nephrotoxicity than AmB-deoxycholate. A new treatment method of AmB in the clinic, such as short-course high-dose treatment, was also developed to improve the curative effect (Jarvis et al., 2019).

Recently, the developments in metabolic engineering, synthetic biology, and bioinformatics have increased the ability to exploit new secondary metabolism or increase the production of secondary metabolites (Brakhage and Schroeckh, 2011; Bilyk and Luzhetskyy, 2016; Ausländer et al., 2017). However, it is still expensive and time-consuming to construct an industrial strain. Besides, a rational design requires the combination of bioinformatics analysis and existing metabolic pathway modification. Except for some model bacteria, most bacteria have limited bioinformatics analysis and tools for genetic modification, such as some unknown gene clusters and a few tools for genetic manipulation of Streptomyces (Amara et al., 2018). Traditional mutagenesis methods, such as chemical mutagenesis using $N$-methyl- $N$-nitroso- $N^{\prime}$ nitrosoguanidine (NTG) or ethyl methanesulfonate (EMS) and physical mutagenesis using ultraviolet (UV) light or X-rays, are still simple and effective methods to generate a high yield of product strains (Baltz, 2016). The efficient screening method is one of the main routes to improve the strain without a comprehensive understanding of various factors affecting the product yield (Parekh et al., 2000; Feng et al., 2019). In addition, combined with the bioinformatics, the analysis of superior mutagenesis strains can explain the mechanism for high yield and provide theoretical guidance for the subsequent improvement of metabolic engineering (Kim et al., 2018).
Gene microarrays are used to obtain the sequence information of mRNA by hybridization between the probe with known sequence and the sample mRNA. If the sample mRNA has never been reported before, there will be no corresponding probe sequence and the new mRNA cannot be detected. In addition, the background noise of nucleic acid hybridization is very high, which affects the accuracy of sequencing. As the high-throughput sequencing technology becomes mature, RNAsequencing (RNA-seq) is a recently developed approach for transcriptome profiling and is popularly applied in bacteria. RNA-seq technology, which is the reverse transcription of mRNAs into the cDNA library and then sequencing, detects gene expression more sensitively than microarrays. With reference genomes, the genome structural variations and genome-wide gene expression abundance can also be analyzed (Wang et al., 2009).

In this study, $S$. nodosus ATCC14899 was mutated by UV combined with NTG. A strain with high-yield AmB was obtained and named S. nodosus ZJB2016050. After observation of the characterization, it was found that the AmB yield, appearance, and color of S. nodosus ZJB2016050 were significantly different from those of the wild-type strain. By comparing the transcriptome analysis, the reasons for high yield were discussed. This work can provide a theoretical basis for the metabolic engineering of $S$. nodosus.

\section{MATERIALS AND METHODS}

\section{Bacterial Strains, Medium, and Culture}

S. nodosus ATCC 14899 (S. nodosus ZJB20130827) was isolated from soil sample. AmB high-yield mutagenic $S$. nodosus ZJB2016050 (S. nodosus N3) was obtained by NTG-UV treatment using an S. nodosus ATCC 14899 spore (Zhang et al., 2018). S. nodosus strains were cultured in a liquid GYM (glucose yeast extract-malt extract) medium and on a GYM agar medium for culture and sporulation, respectively. Isolation and purification of the mutation were carried out on a GYM agar medium at $28^{\circ} \mathrm{C}$ for 4-10 days (Kieser et al., 2000).

\section{UV-Irradiation and NTG Mutagenesis}

A total of $10 \mathrm{~mL}$ flesh spore suspension was collected and then exposed to $15 \mathrm{~W}$ of UV irradiation at $254 \mathrm{~nm}$ for $1 \mathrm{~min}$ with a $20 \mathrm{~cm}$ distance. The spore suspension after UV irradiation was collected to a recovery medium $(8 \mathrm{~g} / \mathrm{L}$ yeast extract, $20 \mathrm{~g} / \mathrm{L}$ glucose, and $2 \mathrm{~g} / \mathrm{L}$ peptone) and incubated for $24 \mathrm{~h}$ at $28^{\circ} \mathrm{C}$. Then, the spores were collected in a $50 \mathrm{mM}$ PBS buffer. One milliliter of the spore suspension was treated with $5 \mathrm{mg} / \mathrm{mL}$ NTG for $30 \mathrm{~min}$. The treated spores were spread on a GYM agar medium at $28^{\circ} \mathrm{C}$ for 6-10 days (Zhang et al., 2018). The colonies that survived were screened using Saccharomyces cerevisiae $\mathrm{X}-33$ as the indicator organism. The colonies of positive mutagenesis were verified using high-performance liquid chromatography (HPLC). 


\section{Fermentation, Amphotericin Analysis, and Electron Microscopy of Mycelium}

The spore solution was cultivated in a seed medium $(15 \mathrm{~g} / \mathrm{L}$ peptone, $10 \mathrm{~g} / \mathrm{L}$ glucose, $10 \mathrm{~g} / \mathrm{L}$ yeast extract, $5 \mathrm{~g} / \mathrm{L} \mathrm{NaCl}$, and $\left.1 \mathrm{~g} / \mathrm{L} \mathrm{CaCO}_{3}\right)$ and incubated at $25^{\circ} \mathrm{C}$ shaking at $200 \mathrm{rpm}$ for 2 days. A total of $2 \mathrm{~mL}$ fresh hyphae culture was transferred to a fermentation medium (25 g/L cotton-seed meal, $69 \mathrm{~g} / \mathrm{L}$ glucose, $9 \mathrm{~g} / \mathrm{L} \mathrm{CaCO}_{3}$, and $0.1 \mathrm{~g} / \mathrm{L} \mathrm{KH}_{2} \mathrm{PO}_{4}$ ) and incubated at $25^{\circ} \mathrm{C}$ shaking at $200 \mathrm{rpm}$ for 4 days (Zhang et al., 2018). Amphotericin was extracted by DMSO (dimethylsulfoxide) and shaking at $25^{\circ} \mathrm{C}$ for $20 \mathrm{~min}$. The mixture was centrifuged at $10,000 \mathrm{rpm}$ for $10 \mathrm{~min}$, and the supernatant was used for HPLC analysis. The HPLC system was an LDC 3200 analytical system (LDC Analytical Inc., New York, USA) with a UV-VIS detector (Yilite Analytical Inc., Dalian, China). The column was an Agilent C18 reversed-phase column $(5 \mu \mathrm{m}, 4.6 \times 150 \mathrm{~mm}$, Agilent Technologies Inc., Santa Clara, CA, USA), and the mobile phase was methanol/acetonitrile/water (4:7:9/v:v:v). AmA was detected at $304 \mathrm{~nm}$, and $A m B$ was detected at $405 \mathrm{~nm}$. Pure samples of $\mathrm{AmB}$ and AmA were purchased from Sigma-Aldrich (St. Louis, MO, USA). The model of the electron microscope is the SU8010 Scanning Electron Microscope (Hitachi, TKY, JPN).

\section{RNA Isolation and q-PCR}

Total RNA isolation of S. nodosus ATCC14899 and S. nodosus ZJB2016050 was prepared using a Trizol reagent. The $S$. nodosus strains were cultured in a fermentation medium, and the fresh mycelium was collected at $72 \mathrm{~h}$. The mycelium pellets were resuspended with a $200 \mu \mathrm{L}$ TE buffer $(10 \mathrm{mM}$ Tris- $\mathrm{HCl}, 1 \mathrm{mM}$ EDTA), which contains lysozyme $(3 \mathrm{mg} / \mathrm{ml})$ and incubated at $25^{\circ} \mathrm{C}$ for $5 \mathrm{~min}$. Then $1.5 \mathrm{ml}$ Trizol was added and shaken violently for $3 \mathrm{~min}$, and incubated at $25^{\circ} \mathrm{C}$ for $5 \mathrm{~min}$. The samples were then centrifuged at $10,000 \mathrm{rpm}$ and $4^{\circ} \mathrm{C}$ for $5 \mathrm{~min}$. The supernatant was transferred to $2.0 \mathrm{~mL}$ EP tubes containing 200 $\mu \mathrm{L}$ of chloroform/isoamyl alcohol. The mixture was vortexed, incubated for $1 \mathrm{~min}$ at $25^{\circ} \mathrm{C}$, and centrifuged at $10,000 \mathrm{rpm}$ and $4^{\circ} \mathrm{C}$ for $10 \mathrm{~min}$. After the phase separation, the supernatant was removed into an EP tube. After adding equal volume isopropanol, the mixture was incubated at $-20^{\circ} \mathrm{C}$ for $1 \mathrm{~h}$ and then centrifuged at $13,600 \mathrm{rpm}$ and $4^{\circ} \mathrm{C}$ for $20 \mathrm{~min}$. The supernatant was removed, and the resulting pellets were washed with $75 \%$ ethanol and then centrifuged at $10,000 \mathrm{rpm}$ and $4^{\circ} \mathrm{C}$ for $3 \mathrm{~min}$. The supernatant was removed and the resulting pellets were dried at $37^{\circ} \mathrm{C}$ for $5 \mathrm{~min}$ and resuspended in $100 \mu \mathrm{L} \mathrm{DEPC} \mathrm{H}_{2} \mathrm{O}$. The samples were treated with DNase I at $37^{\circ} \mathrm{C}$ for $30 \mathrm{~min}$. The samples were added with $150 \mu \mathrm{L}$ phenol/chloroform/isoamyl alcohol (25:24:1/v:v:v), then vortexed and centrifuged at $13,600 \mathrm{rpm}$ for $15 \mathrm{~min}$. The aqueous phase was removed into an EP tube and added with 400 $\mu \mathrm{L} 0.3 \mathrm{M}$ sodium acetate, then centrifuged at $10,000 \mathrm{rpm}$ and $4^{\circ} \mathrm{C}$ for $15 \mathrm{~min}$. The resulting sediment was washed twice with $75 \%$ ethanol and then dried at $37^{\circ} \mathrm{C}$ and resuspended in $100 \mu \mathrm{L} \mathrm{DEPC}$ $\mathrm{H}_{2} \mathrm{O}$. The isolated RNA was stored at $-80^{\circ} \mathrm{C}$.

The q-PCR was used to verify the accuracy of transcriptome sequencing. The biologically replicated samples are extracted with total RNA. One microgram total RNA of each sample was treated with HiScript Q RT SuperMix for qPCR (Vazyme,
NanJing, CHN) to prepare cDNA. ChamQ Universal SYBR qPCR Master Mix (Vazyme, NanJing, CHN) was used for q-PCR process on an ANALYTIKJENA QTOWER real-time fluorescent quantitative PCR instrument (Analytik Jena AG, Jena, GER).

\section{Transcriptome Library Construction}

One microgram of the total RNA sample was treated with a Ribo-Zero ${ }^{\mathrm{TM}}$ Magnetic Gold Kit (Illumina, San Diego, CA, USA) to deplete the rRNA, and then the protocol of TruSeq RNA Sample Prep Kit v2 (Illumina, San Diego, CA, USA) was followed to construct the libraries. The first-strand cDNA is generated by First Strand Master Mix and Super Script II (Invitrogen, Carlsbad, CA, USA) reverse transcription with the following reaction condition: $25^{\circ} \mathrm{C}$ for $10 \mathrm{~min} ; 42^{\circ} \mathrm{C}$ for $50 \mathrm{~min}$; $70^{\circ} \mathrm{C}$ for $15 \mathrm{~min}$. The product was purified and added with a Second Strand Master Mix and a dATP, dGTP, dCTP, dUTP mix to synthesize the second-strand cDNA at $16^{\circ} \mathrm{C}$ for $1 \mathrm{~h}$. The purified fragmented cDNA combine with an End Repair Mix was incubated at $30^{\circ} \mathrm{C}$ for $30 \mathrm{~min}$. The end-repaired DNA was purified with Ampure XP Beads and added with an A-Tailing Mix, mixed by pipetting and incubated at $37^{\circ} \mathrm{C}$ for $30 \mathrm{~min}$. The adenylate $3^{\prime}$ ends DNA and an RNA Index Adapter and Ligation Mix were combined and mixed well by pipetting, and then incubated at $30^{\circ} \mathrm{C}$ for $10 \mathrm{~min}$. The end-repaired DNA was purified with Ampure XP Beads and added with the Uracil$\mathrm{N}$-Glycosylase enzyme. The product was incubated at $37^{\circ} \mathrm{C}$ for $10 \mathrm{~min}$ and purified AGENCOURT Ampure XP Beads. Several rounds of PCR amplification with a PCR Primer Cocktail and a PCR Master Mix are performed to enrich the cDNA fragments. Then the PCR products are purified with Ampure XP Beads. The libraries' quality and quantity are assessed in two methods: by checking the distribution of the fragment size using the Agilent 2100 bioanalyzer instrument (Agilent DNA 1000 Reagents, Agilent Technologies Inc., CA, USA), and by quantifying the library using real-time quantitative PCR (QPCR) (TaqMan Probe, Thermo Fisher Scientific, Waltham, MA, USA). The qualified libraries will amplify on cBot to generate the cluster on the flowcell (TruSeq PE Cluster Kit V3-cBot-HS, Illumina, San Diego, CA, USA). Furthermore, the amplified flowcell will be sequenced on the HiSeq 2000 System (TruSeq SBS KITHS V3, Illumina); a read length of 90 is the most common sequencing strategy.

\section{Bioinformatics Analysis of Sequencing Reads}

The sequenced raw reads were filtered to get clean reads and mapped to the S. nodosus ATCC14899 genome (Genebank ID: NZ_CP009313) using HISAT v2.0.1-beta (Kim et al., 2015). The clean reads were aligned to the reference gene using Bowtie (http://bowtie-bio.sourceforge.net/Bowtie2/index. shtml), and the gene expression levels were calculated using RSEM (http://deweylab.biostat.wisc.edu/RSEM). The screening of differentially expressed genes was analyzed by the PossionDis method in this study because it allows samples with no replicates (Audic and Claverie, 1997). 


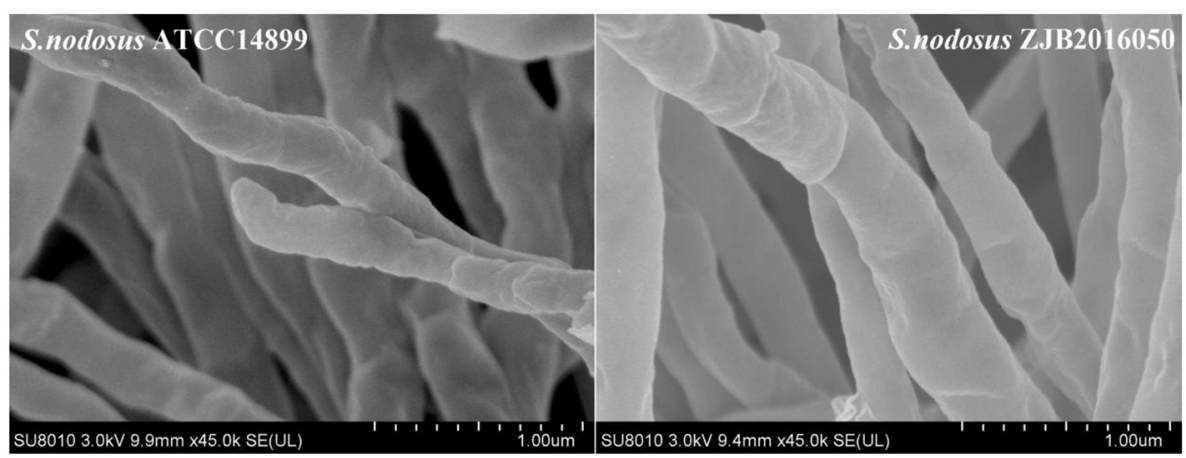

FIGURE 1 | Electron micrographs of the mycelium of S. nodosus ATCC14899 and S. nodosus ZJB2016050; the minimum scale was $1 \mu$ m.

$$
\mathrm{p}(\mathrm{x})=\frac{\mathrm{e}^{-\lambda} \lambda^{\mathrm{x}}}{\mathrm{X} !}
$$

$\mathrm{X}$ refers to the reads number of the corresponding gene. The screening criteria for significantly differentially expressed genes were abs $\log _{2}$ (FoldChange) $\geq 1$ and FDR $\leq 0.005$.

The pathway significant enrichment analysis refers to the KEGG (Kyoto Encyclopedia of Genes and Genomes) pathway database in this study.

$$
\mathrm{P}=1-\sum_{i=0}^{m-1} \frac{\left(\begin{array}{c}
\mathrm{M} \\
i
\end{array}\right)\left(\begin{array}{c}
\mathrm{N}-\mathrm{M} \\
n-i
\end{array}\right)}{\left(\begin{array}{c}
\mathrm{N} \\
n
\end{array}\right)}
$$

$\mathrm{N}$ refers to the number of genes with pathway annotation in all genes. $n$ is the number of differentially expressed genes (or target genes) in N. M refers to the number of genes annotated as a specific pathway in all genes. $m$ is the number of significantly differentially expressed genes (or target genes) noted in a particular pathway. A pathway with $Q \leq 0.05$ was defined as that was significantly enriched in significantly differentially expressed genes. Through pathway significant enrichment, the significantly differentially expressed genes of major metabolic pathways and signal transduction pathways can be identified.

The GO (Gene Ontology) function enrichment analysis refers to the Gene Ontology database (http://www.geneontology. org/) using the GO Termfinder (http://www.yeastgenome.org/ help/analyze/go-term-finder). The calculation formula of GO enrichment analysis is similar to that of KEGG enrichment. A GO term with $P \leq 0.05$ was defined as a GO term that was significantly enriched in significantly different genes. The GO functional significance enrichment analysis was used to determine the biological functions of the significantly different genes.

\section{RESULTS}

\section{Mutagenesis Results and Morphological Observation}

The spore morphology of the mutant strains was classified into three types. The mutant strains of type 1 had no spores, and the color was yellowish. The shape of the colony on the agar medium was deplanate. This kind of mutant colonies may have some internal dysfunction, although not fatal; the rate of growth and spore formation have been affected. The overall level of growth was slower than the original strain, and the positive mutation rate was low. The color of the type 2 mutant strains was yellow, and the shape was convex. The type 2 colonies generated black spores, and the positive mutation rate was $15.8 \%$, which is higher than that of type 1 . The type 3 mutant was the best kind of mutant strains with a positive mutation rate of $72.6 \%$. The color of the colonies was yellowish, and the shape was convex. The type 3 mutant generated the common spores, which became gray at 2-3 days. The bulge in colony morphology means that the mutant strains of the latter two types have little effect on the growth rate, which is similar to the original strain S. nodosus ATCC14899, while the difference in the spore color is likely related to the intracellular pigment, which is likely related to the mass of the spores. Among the three types of mutagenesis, the $\mathrm{AmB}$ production of types 1 and 2 mutagenesis clones was not significant, and the yield was about the same as the original strain. The high-yield mutant S. nodosus ZJB2016050 from type 3 mutagenesis was screening out for culture. The seed liquid of S. nodosus ZJB2016050 was reddish, and the mycelium was granular. In contrast, the seed solution of S. nodosus ATCC14899 was yellow, and the shape is globular (Supplementary Figure 1). The agar diffusion assay screening method is shown in Supplementary Figure 2. The characteristic and the positive mutant rate were listed in Supplementary Table 1.

\section{Electron Microscopy and Fermentation Analysis}

The result of electron microscope screening for S. nodosus ZJB2016050 and S. nodosus ATCC14899 is shown in Figure 1. At a magnification of $45,000 \times$, the mycelium of $S$. nodosus ZJB2016050 was found to be significantly thicker than the mycelium of S. nodosus ATCC14899.

The mutation S. nodosus ZJB2016050 and the origin $S$. nodosus ATCC14899 were fermented in a shaking flask, and the parameters including $\mathrm{AmB}$ yield, dry cell weight, and residue glucose were compared (Figure 2). The mutant strain had some 

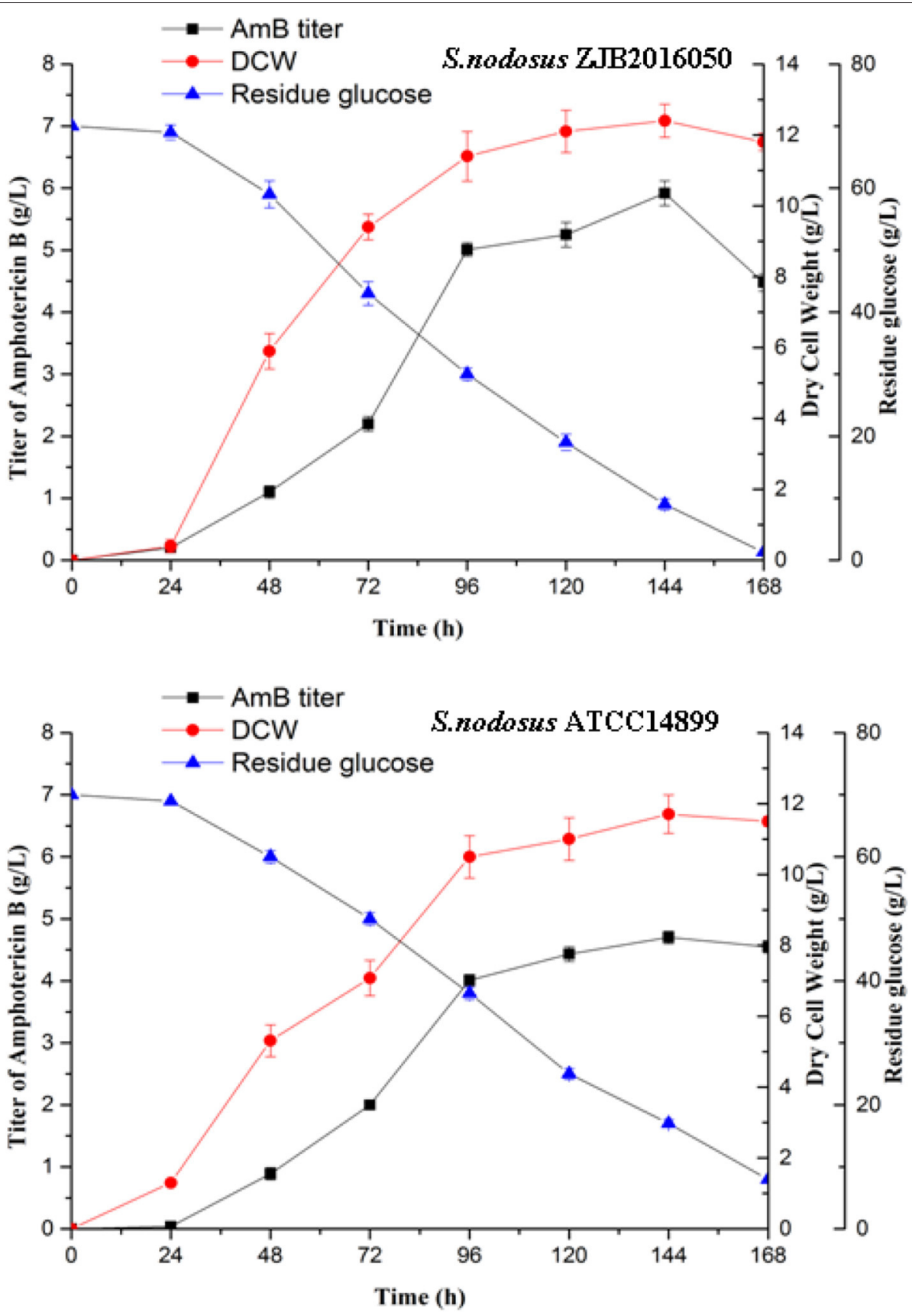

FIGURE 2 | The shake flask fermentation process of S. nodosus ATCC14899 and S. nodosus ZJB2016050. Black squares represent AmB titer, red circles represent DCW, and blue triangles represent residue glucose.

TABLE 1 | The quality summary of filtered reads.

\begin{tabular}{lcccccc}
\hline Sample & $\begin{array}{c}\text { Total raw } \\
\text { reads }(\mathbf{M b})\end{array}$ & $\begin{array}{c}\text { Total clean } \\
\text { reads }(\mathbf{M b})\end{array}$ & $\begin{array}{c}\text { Total clean } \\
\text { based (Gb) }\end{array}$ & $\begin{array}{c}\text { Clean reads } \\
\text { Q30 (\%) }\end{array}$ & $\begin{array}{c}\text { Low quality } \\
\text { reads (\%) }\end{array}$ & $\begin{array}{c}\text { Adapter } \\
\text { reads (\%) }\end{array}$ \\
\hline ZJB2016050 & 11.43 & 8.77 & 1.31 & 90.76 & 15.35 & 7.92 \\
ATCC14899 & 11.43 & 8.83 & 1.32 & 90.40 & 18.11 & 4.63 \\
\hline
\end{tabular}

Q30 reads mean a mass value $>30$, which indicates a base error rate of $0.1 \%$. 
advantages in the growth and had a longer exponential growth period than the wild type. Both strains grew most rapidly in the $24-96 \mathrm{~h}$ period. The cotton-seed meal is in the form of granules, which is helpful to reduce clumping during the fermentation of $S$. nodosus. Both of the strains growth and the amphotericin synthesis required glucose. The detection of residue glucose accurately reflected the ability of $S$. nodosus. From the fermentation process curve, the glucose consumption rate of the high-yield S. nodosus ZJB2016050 was accelerated. The glucose was almost consumed at $168 \mathrm{~h}$, while the residue glucose of the origin S. nodosus ATCC14899 was $7.9 \mathrm{~g} / \mathrm{L}$. The accumulation of amphotericin was accompanied by the increase in biomass and seemed to be related to the biomass. The AmB yield of S. nodosus ZJB2016050 peaked at $144 \mathrm{~h}$ and declined thereafter, which was due to the low glucose concentration leading to nutrient deficiency. The yield of by-product AmA was tested at $96 \mathrm{~h}$. The $\mathrm{AmA}$ and $\mathrm{AmB}$ fermentation yields of S. nodosus ZJB2016050 were 0.6 and $5.9 \mathrm{~g} / \mathrm{L}$, respectively, while the yields of S. nodosus ATCC14899 were 3.3 and 4.7 g/L, respectively (Supplementary Figure 3). Due to the similar structure and the similar biosynthesis pathways, it often takes more effort to remove AmA in industrial production. Based on the fermentation advantage of S. nodosus ZJB2016050, it is meaningful to compare transcriptome analysis in this study.

\section{Analysis of the Transcriptome Reads of S. nodosus}

The poor accuracy reads will affect the subsequent quantitative analysis, and the reads with a high content unknown base also interfere with the analysis of the reliability ( $\mathrm{Li}$ et al., 2008; Cock et al., 2009). To ensure the quality of the information analysis, the original data in low quality, adapter pollution and the reads with high content unknown base were removed before the data analysis. A total of 8.77 and $8.83 \mathrm{Mb}$ clean reads were obtained from S. nodosus ZJB2016050 and S. nodosus ATCC14899, respectively. The percentage of low-quality reads of S. nodosus ZJB2016050 and S. nodosus ATCC14899 were 15.35 and $18.11 \%$, respectively. The quality of filtered reads is summarized in Table 1. The distribution of the base content of each sample is shown in Supplementary Figure 4. The base mass distribution of each sample is shown in Supplementary Figure 5. The composition profile of total raw reads is shown in Supplementary Figure 6.

The comparison rate with reference genome is one of the important indexes to evaluate transcriptome sequencing data. The comparison ratio of each sample was above 95\%. The unique match rate of S. nodosus ZJB2016050 and S. nodosus ATCC14899 was 95.30 and $93.59 \%$, respectively. Normally, sequencing reads evenly covered all positions of the whole length of the genome; however, the distribution of reads was affected by sample degradation, RNA fragmentation bias, and PCR amplification bias. The homogeneity of sequencing results

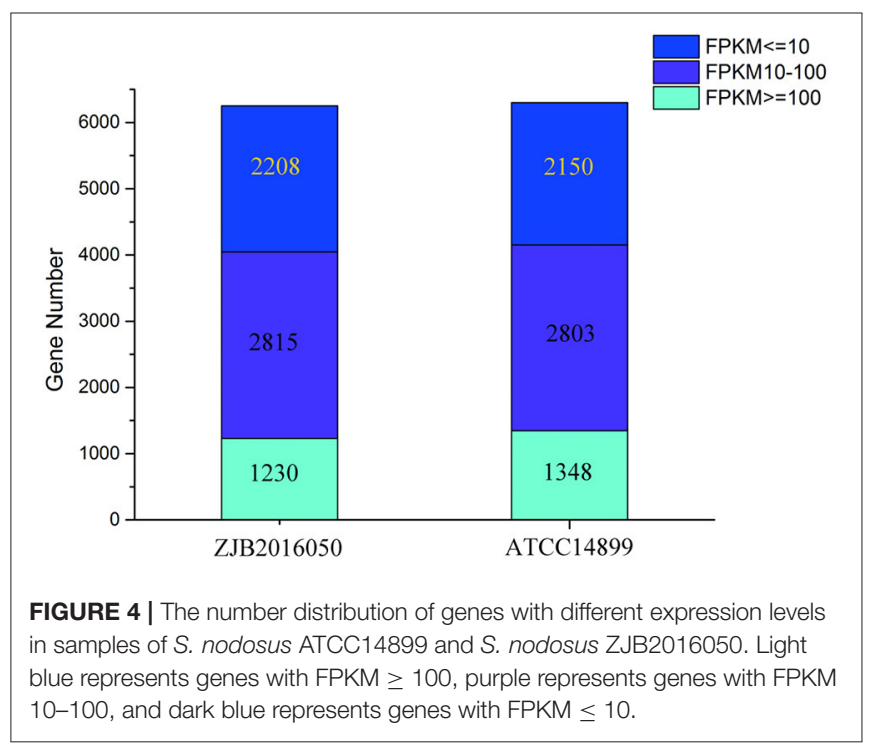

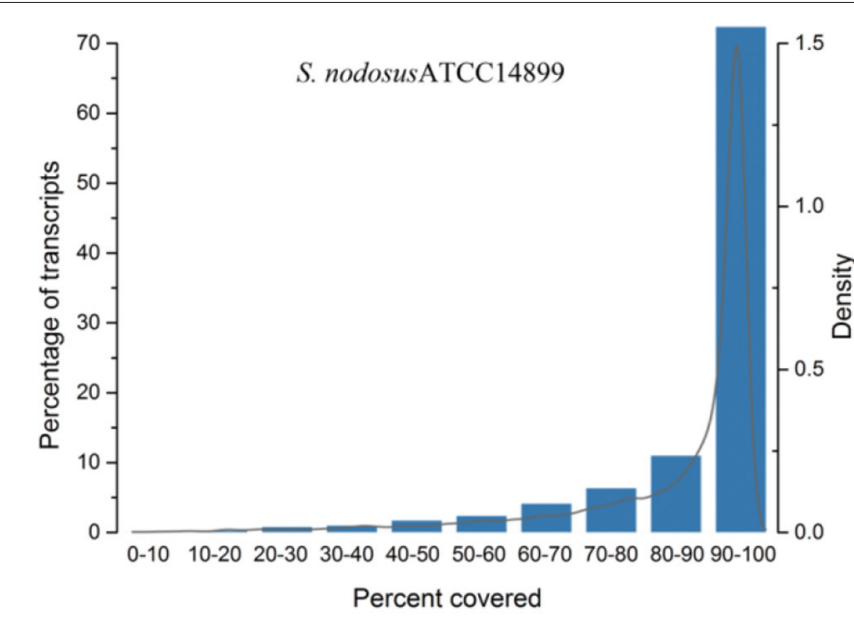

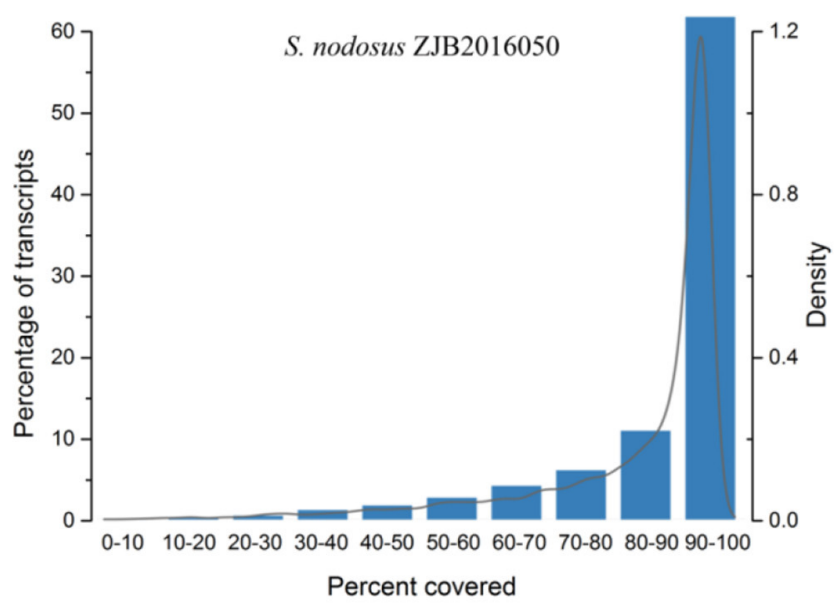

FIGURE 3 | The genes coverage of samples of S. nodosus ATCC14899 and S. nodosus ZJB2016050. 


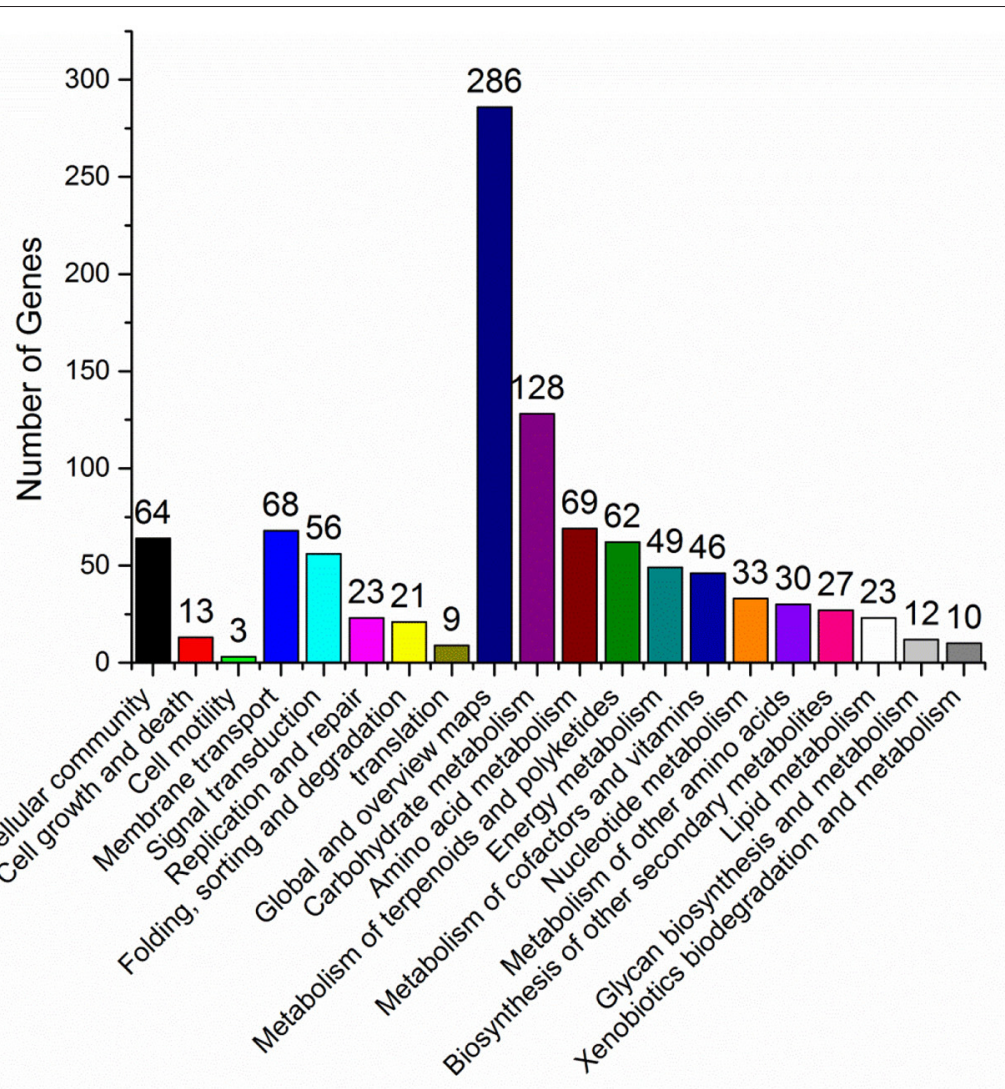

FIGURE 5 | KEGG pathway classification map of significantly differentially expressed genes.

is shown in Supplementary Figure 7, which displays the reads distribution in the $5^{\prime}-3^{\prime}$ regions of all the genes of the samples. There was no obvious peak in Supplementary Figure 7, which indicates that the sequencing results are relatively uniform. The gene coverage of each sample is shown in Figure 3. As the peak value in the figure was on the right, it indicates that the gene coverage was good; otherwise, there may be insufficient data or bias. For samples with good quality and enough sequencing data, most of the genes would be fully covered.

\section{Gene Expression Pattern Analysis for S. nodosus}

The number distribution of genes with different expression levels in each sample is shown in Figure 4. The value of fragments per kilobase million mapped reads (FPKM) is represented for the gene expression. Among the expression genes, a total of 6,103 genes were common genes, and 149 and 193 genes were the number of unique genes for S. nodosus ZJB2016050 and S. nodosus ATCC14899, respectively (Supplementary Figure 8). If there are significant phenotypic or functional differences between the two strains, it is usually due to the differences in gene expression between the two samples. Therefore, the comparative analysis of differentially expressed genes is often the most important content in comparative transcriptome. Among the difference expression genes (DEGs), 414 genes of $S$. nodosus
ZJB2016050 were upregulated and 660 genes were downregulated (Supplementary Figure 9).

In vivo, different genes coordinate their biological functions. Pathway-based analysis could identify the major biochemical pathways and signal transduction pathways with significantly DEGs. Among the significantly DEGs between S. nodosus ZJB2016050 and $S$. nodosus ATCC14899, the metabolic classification with the largest number of DEGs was global metabolism, and carbohydrate metabolism also had large different expressed genes with 123 genes in total (Figure 5). In addition, the number of DEGs associated with polyketides metabolism was 68 , which was also a relatively large number of differentially expressed genes. Amphotericin is one of the polyketides, and the potential reasons for the yield differences may lie in these DEGs. About 11 genes are involved in cell growth and death, which is a relatively small number.

There are three ontologies in GO that describe the molecular function, cell component, and biological process of genes, respectively. GO function enrichment analysis gives the GO function items that are enriched in the significantly DEGs compared with the genomic background to show which biological functions are correlated with the significantly DEGs. In biological process ontology, the most different item was metabolic process with 375 DEGs, and cellular process was the second most different item with 223 DEGs (Figure 6). 


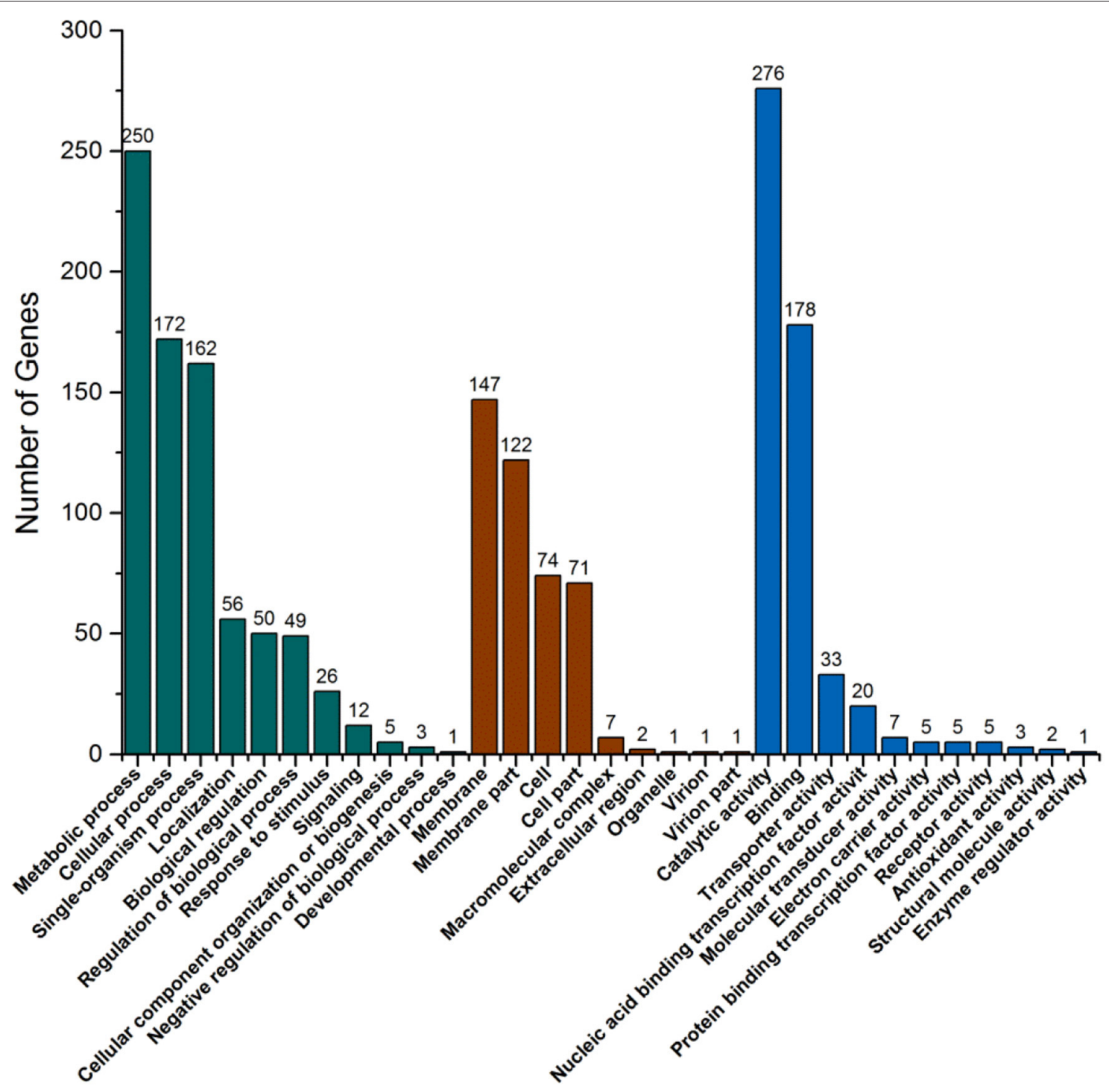

FIGURE 6 | GO function classification map of significantly differentially expressed genes.

These large differences are probably the main reason for the growth differences between strains. In cell component ontology, membrane and membrane part items had significant differences with 201 and 192 DEGs, respectively. In molecular function ontology, the most different item was catalytic activity with 403 DEGs. This may indicate that the pathway with these DEGs is likely to be regulated. Combined with the KEGG pathway and GO analysis, the functional localization of DEGs was relatively accurate. This can help to provide reliable bases for speculating about the causes of the strain differences.

\section{Carbohydrate Metabolic Pathway Analysis}

Carbohydrate metabolism is one of the main metabolic pathways and energy supply in bacteria, including the precursor supplying of polyketides synthesis, intracellular reductive-power supplying, energy metabolism, etc. (Yang et al., 2013; Kwak and Jin, 2017; Liu et al., 2019). The fermentation of amphotericin takes glucose as the only carbon source in this study, and it is necessary to analyze the carbohydrate metabolism pathway.

The pathway from glucose to acetyl-CoA was significantly upregulated at three nodes, including glucose to $\mathrm{D}$-glucose6P (G6P), glycerate-3P (G3P) to glycerate-2P (G2P), and pyruvate to acetyl-CoA. The expression of SNOD_RS25490 and SNOD_RS32555 genes, which were identified as sugar kinase and participated in the step from glucose to G6P, had an increase of 1.6- and 1.4-fold ( $\log 2$ FPKM/FPKM). SNOD_RS24025 and SNOD_RS06850 genes were identified as phosphoglycerate mutase participating in step G3P to G2P with an increase of 1.9and 2.0-fold ( $\log _{2}$ FPKM/FPKM), respectively. SNOD_RS16815 and SNOD_RS16810 were identified as pyruvate dehydrogenase and increased 1.7 - and 1.2-fold ( $\log _{2}$ FPKM/FPKM), respectively (Figure 7). 


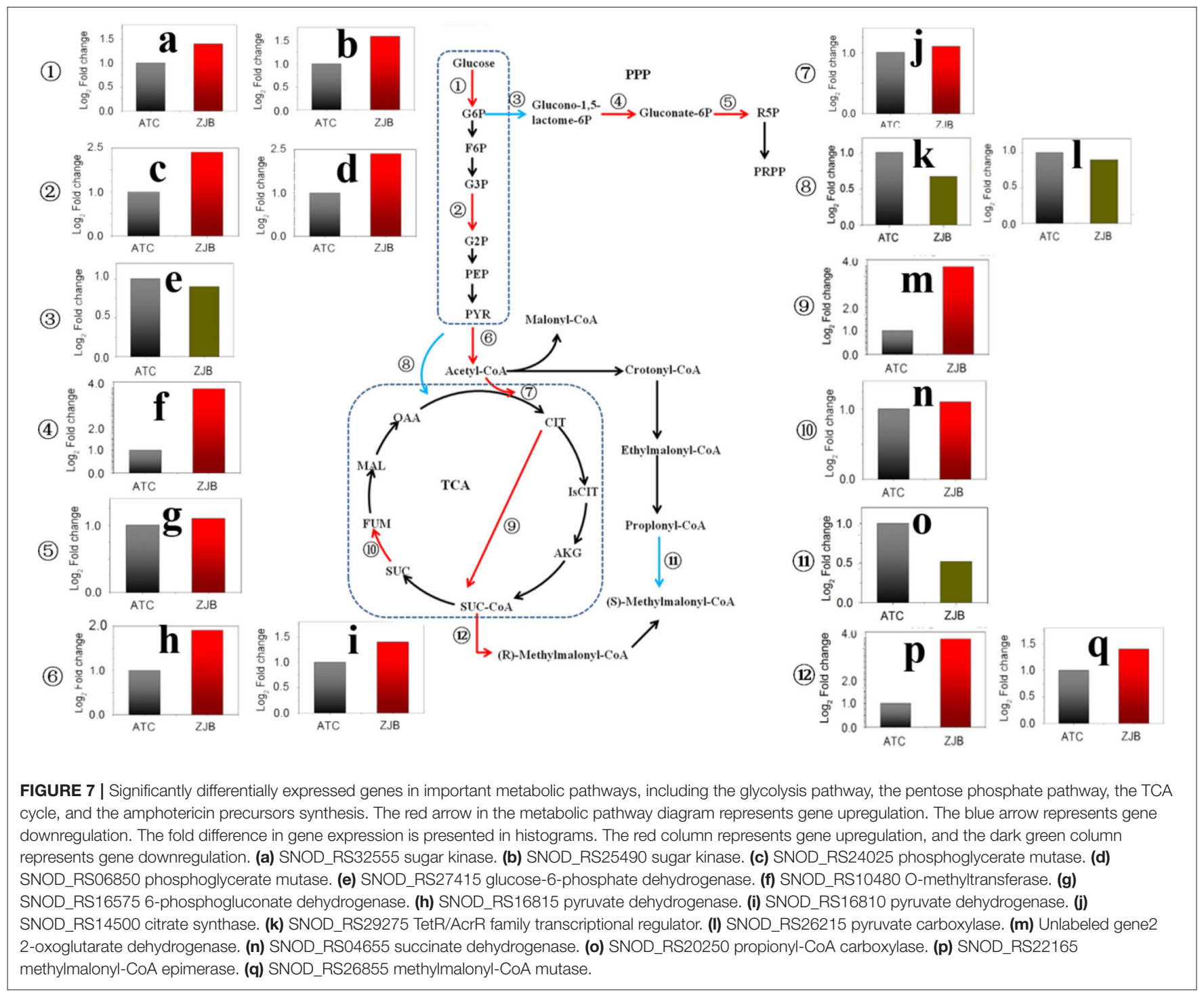

As acetyl-CoA enters the tricarboxylic acid cycle (TCA), the expression of SNOD_RS14500 gene (citrate synthase) and unlabeled gene 2 (2-oxoglutarate dehydrogenase) was upregulated by 1.1 -fold $\left(\log _{2}\right.$ FPKM/FPKM) and 3.8fold $\left(\log _{2}\right.$ FPKM/FPKM), respectively. The 2-oxoglutarate dehydrogenase participated in step from 2-oxoglutarate to succinyl-dihydrolipoamide. This could lead to increased accumulation of succinyl-CoA. Besides, the expressions of methylmalonyl-CoA epimerase (SNOD_RS22165) and methylmalonyl-CoA mutase (SNOD_RS26855) in the pathway from succinyl-CoA to methylmalonyl-CoA were increased. In contrast, the amount of propionyl-CoA that flows to methylmalonyl-CoA may be reduced due to a 2.1 -fold $\left(\log _{2}\right.$ FPKM/FPKM) reduction for propionyl-CoA carboxylase (SNOD_RS20250) (Figure 7).

The pentose phosphate pathway (PPP) is the main metabolic pathway in which bacteria acquire NADPH in the cell. Two genes with significantly different expression were glucose-6-phosphate dehydrogenase (SNOD_RS27415) and 6-phosphogluconate dehydrogenase (SNOD_RS16575), and both of them are on metabolic catalytic reaction to produce NADPH (Figure 7). In the step from G6P to glucono-1,5-lactone-6P, SNOD_RS27415 gene was downregulated by one-fold $\left(\log _{2}\right.$ FPKM/FPKM). In the step from D-gluconate-6P to D-ribulose-5P, the SNOD_RS16575 gene was upregulated by 1.1 -fold $\left(\log _{2}\right.$ FPKM/FPKM).

\section{Multiple Genes or Metabolic Pathways Analysis The Most Significant Difference Expressions Attributive Metabolic Pathway}

Among the significant gene expression differences between highyielding strains and wild-type strains, the first 20 upregulated and downregulated genes with the greatest difference were selected (Table 2). In the S. nodosus database, the functions of multiple genes or proteins have not been identified, and a total of 18 genes were considered as hypothetical protein. 
TABLE 2 | List of the top 20 genes of S. nodosus ZJB2016060 with the most differences in upregulated genes and downregulated genes, respectively.

\begin{tabular}{|c|c|c|c|}
\hline Gene tag & $\begin{array}{l}\text { Gene } \\
\text { length }\end{array}$ & Product & $\begin{array}{c}\log _{2} \text { Fold } \\
\text { change }\end{array}$ \\
\hline Unlabeled gene 3 & 189 & Hypothetical protein & 14.00 \\
\hline SNOD_RS08105 & 186 & Hypothetical protein & 12.74 \\
\hline SNOD_RS33220 & 297 & Ferredoxin & 12.16 \\
\hline SNOD_RS27215 & 426 & Serine/threonine protein kinase & 11.94 \\
\hline SNOD_RS25090 & 588 & Serine/threonine protein kinase & 11.38 \\
\hline SNOD_RS29130 & 333 & Hypothetical protein & 11.34 \\
\hline SNOD_RS19855 & 579 & RNA polymerase & 10.08 \\
\hline SNOD_RS32210 & 822 & Hypothetical protein & 9.64 \\
\hline Unlabeled gene 4 & 1,293 & Transposase & 9.21 \\
\hline SNOD_RS32200 & 1,464 & Hypothetical protein & 8.28 \\
\hline SNOD_RS33715 & 1,992 & Hypothetical protein & 8.06 \\
\hline SNOD_RS26455 & 936 & Hypothetical protein & 7.78 \\
\hline SNOD_RS26450 & 1,896 & Hypothetical protein & 7.32 \\
\hline SNOD_RS14330 & 942 & $\begin{array}{l}30 S \text { ribosomal protein S6 } \\
\text { modification protein RimK }\end{array}$ & 7.31 \\
\hline SNOD_RS19985 & 873 & $\begin{array}{l}\text { Phosphate ABC transporter } \\
\text { ATP-binding protein }\end{array}$ & 7.09 \\
\hline SNOD_RS19980 & 909 & Hypothetical protein & 6.59 \\
\hline SNOD_RS14335 & 312 & Hypothetical protein & 6.38 \\
\hline SNOD_RS19960 & 1,758 & $\begin{array}{l}\text { Phosphate ABC transporter } \\
\text { substrate-binding protein }\end{array}$ & 6.07 \\
\hline SNOD_RS19965 & 2,715 & Hypothetical protein & 5.97 \\
\hline SNOD_RS19950 & 990 & $\begin{array}{l}\text { Phosphate ABC transporter } \\
\text { permease subunit PstC }\end{array}$ & 5.55 \\
\hline SNOD_RS26380 & 1,149 & Dehydrogenase & -11.86 \\
\hline SNOD_RS10270 & 312 & Hypothetical protein & -11.78 \\
\hline SNOD_RS34580 & 537 & Hypothetical protein & -11.58 \\
\hline SNOD_RS30730 & 570 & ATP-binding protein & -11.56 \\
\hline SNOD_RS03230 & 510 & Hypothetical protein & -10.48 \\
\hline SNOD_RS30745 & 1,185 & FAD-dependent oxidoreductase & -10.27 \\
\hline SNOD_RS28195 & 969 & Hypothetical protein & -9.29 \\
\hline SNOD_RS32835 & 1047 & Iron $\mathrm{ABC}$ transporter & -9.16 \\
\hline Unlabeled gene 5 & 1,494 & $\alpha, \alpha$-trehalose-phosphate synthase & -6.07 \\
\hline SNOD_RS11045 & 1,122 & FAD-dependent oxidoreductase & -5.96 \\
\hline Unlabeled gene 6 & 1,734 & Trehalose synthase & -5.64 \\
\hline SNOD_RS10530 & 456 & DoxX family protein & -5.56 \\
\hline Unlabeled gene 7 & 885 & dTDP-4-dehydrorhamnose reductase & -5.50 \\
\hline SNOD_RS03660 & 432 & Protease inhibitor protein & -5.06 \\
\hline Unlabeled gene 8 & 1,056 & Sugar kinase & -5.00 \\
\hline SNOD_RS19005 & 888 & Hypothetical protein & -4.61 \\
\hline SNOD_RS33580 & 2,202 & Hypothetical protein & -4.52 \\
\hline SNOD_RS30950 & 639 & $\begin{array}{l}\text { ATP-dependent Clp protease } \\
\text { proteolytic subunit }\end{array}$ & -4.41 \\
\hline Unlabeled gene 9 & 1,212 & Aminobutyrate aminotransferase & -4.30 \\
\hline SNOD_RS30740 & 2,535 & Hypothetical protein & -4.18 \\
\hline
\end{tabular}

Among the upregulated genes, SNOD_RS33220 was ferredoxin, which participates in redox chains and plays an important role in electron transfer processes and various enzymatic reactions (Ta and Vickery, 1992). Both SNOD_RS27215 and SNOD_RS25090 were considered as
TABLE 3 | List of secondary metabolites with similarities higher than $80 \%$ synthesize gene clusters in S. nodosus using antiSMASH.

\begin{tabular}{lllc}
\hline Location of genome & Type & $\begin{array}{l}\text { Most similar } \\
\text { product }\end{array}$ & Similarity (\%) \\
\hline $130,513-153,027$ & Lassopeptide & MS-271 & 100 \\
$173,085-223,697$ & NRPS & Coelichelin & 100 \\
$1,107,947-1,230,950$ & Type II PKS-Type Sapromomycin & 86 \\
& III PKS-NRPS & & \\
2,000,465-2,030,585 & Terpene & Geosmin & 100 \\
$2,903,942-2,924,994$ & Terpene & Albaflavenone & 100 \\
$4,319,873-4,392,382$ & Type II PKS & Spore pigment & 83 \\
$5,011,409-5,023,199$ & Siderophore & Desferrioxamine B & 83 \\
$5,895,139-5,905,534$ & Ectoine & Ectoine & 100 \\
$7,170,189-7,317,853$ & Type I PKS & Amphotericin & 100 \\
\hline
\end{tabular}

serine/threonine protein kinase, and SNOD_RS27215 belongs to the HATPase superfamily, which works as signal transduction (Dufour and Haldenwang, 1994). SNOD_RS32210 was putative NitT/TauT family transport system permease protein that helps S. nodosus to transport nitrate (Omata et al., 1999). SNOD_RS19985, SNOD_RS19960, and SNOD_RS19950 were considered as phosphate $\mathrm{ABC}$ transporters belonging to the ATPase component, the periplasmic component, and the permease component, respectively (Tam and Saier, 1993; Wanner, 1993; Tomii and Kanehisa, 1998).

Among the downregulated genes, SNOD_RS26380 was considered as myoinositol,2-dehydrogenase in streptomycin biosynthesis. The synthesis of streptomycin from D-glucose-6P of the glycolysis pathway has a competitive effect on glucose flow to other pathways (Flatt and Mahmud, 2007). SNOD_RS30745 and SNOD_RS11045 belong to FAD-dependent oxidoreductase and are involved in the halogenation of other polyketides and the mono-oxidation of secondary metabolites. Unlabeled gene 8 considered as sugar kinase was participating in the biosynthesis of other secondary metabolites (the synthetic cluster is partially similar to validamycin).

\section{Difference Expression in Metabolic Pathways of Secondary Metabolites}

The mapping of secondary metabolite synthesis gene clusters was performed with antiSMASH (https://antismash. secondarymetabolites.org) (Medema et al., 2011). Synthesis gene clusters with more than $80 \%$ similarity were analyzed (Table 3 ). The transcriptome expression level of the synthesis gene of the lassopeptide type product MS-271, the siderophore type product desferrioxamine B analog, the ectoine type product ectoine, and the NRPS (non-ribosomal peptide synthetase) type product coelichelin seemed to be low.

An $86 \%$ similarity sapromomycin product was identified to be a combination of types. The type II polyketone synthetase (PKS5) of the sapromomycin analog synthesis gene is considered as a competing branch of type I PKS because it will compete with the synthetic precursor with type I PKS. The type II polyketone synthetase is highly expressed in S. nodosus. By comparison, 


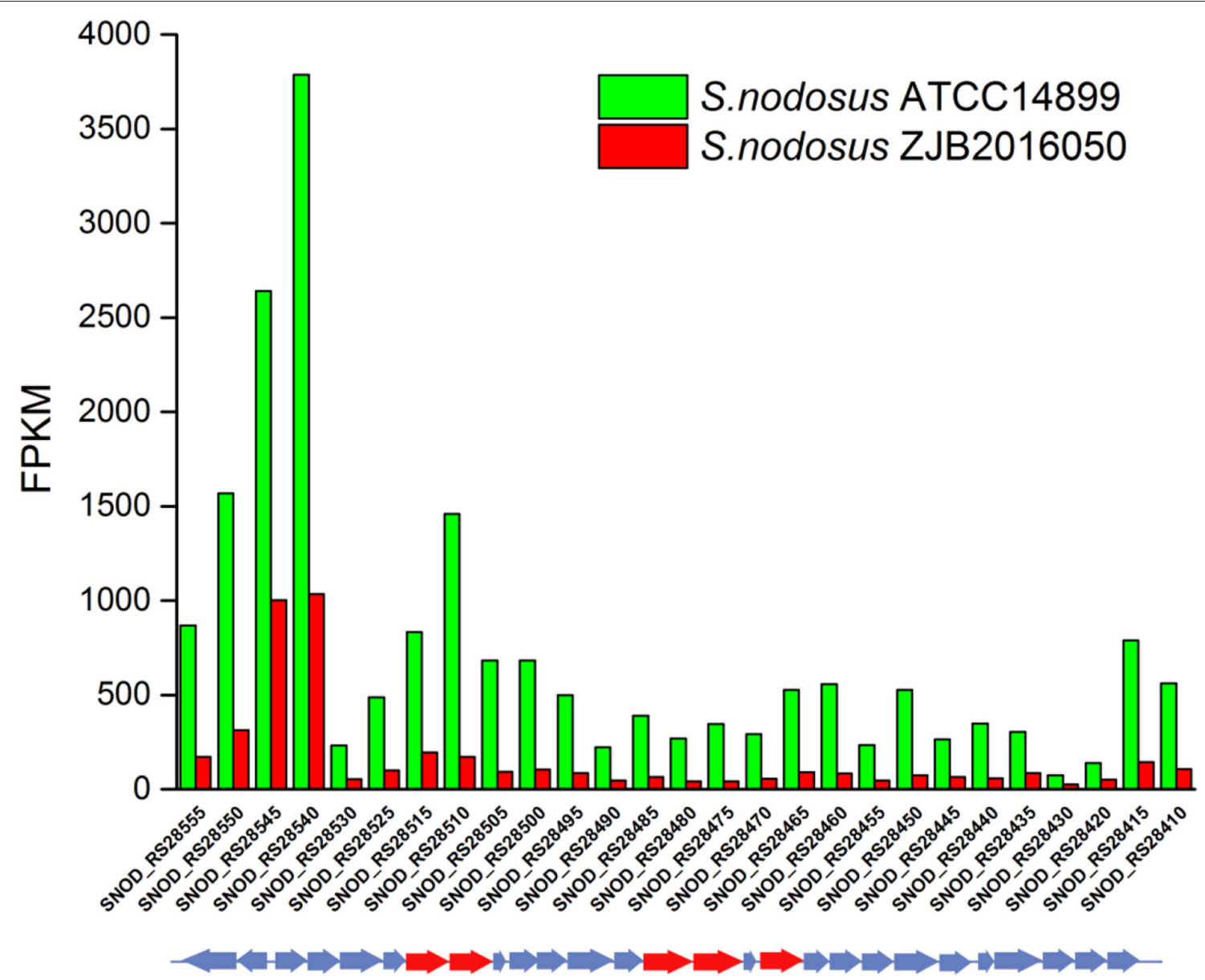

FIGURE 8 | The transcription comparison of the type II polyketone synthetase (PKS5) of the sapromomycin analog synthetic gene cluster of S. nodosus. Green bars indicate sample S. nodosus ATCC14899, and red bars indicate sample S. nodosus ZJB2016050. The red arrows represent the core genes of the synthetic gene cluster.

sapromomycin analog synthesis genes were downregulated in high-yield S. nodosus ZJB2016050 (Figure 8). Based on the metabolic pathway prediction of the KEGG pathway, it was found that the core genes SNOD_RS28520 and SNOD_RS28515 could use malonyl-CoA to synthesize the skeleton of competing products. This may be one of the important reasons for the high yield.

The synthetic gene cluster of amphotericin was reported (Caffrey et al., 2001). In general, the high-yield S. nodosus ZJB2016050 was slightly downregulated on the amphotericin synthesis gene cluster compared with the wild-type S. nodosus ATCC14899 (Figure 9). The most downregulated gene was SNOD_RS02475, a hypothetical protein defined as ORF2 in amphotericin synthesis whose function is unknown. In highyield S. nodosus ZJB2016050, the expression of the amphA module increased at 0.2 -fold $\left(\log _{2}\right.$ FPKM/FPKM). However, except for the first start module amphA, all the other PKS modules were shown to be slightly downregulated. The amphK module was downregulated significantly, which is the end PKS module of these six PKS modules.
The q-PCR verification of the 25 key genes in this study is shown in Supplementary Figure 10, which involved the glycolysis pathway, the TCA cycle, the PPP pathway, the competitive secondary metabolite (PKS5) synthesis gene cluster, and the amphotericin synthesis gene cluster.

\section{DISCUSSION}

Traditional mutagenesis is one of the main methods for constructing excellent strains, and rapid screening methods can improve the efficiency of screening. In the screening process of mutagenesis, $S$. nodosus with good spore growth are more likely to have excellent mutant strains. We speculate that the excellent morphology of the spores also shows, to a certain extent, whether the mutant strain has good genetic stability. In this study, a mutated high-yield strain S. nodosus ZJB2016050 was obtained in our lab and had greater advantages in industrial production. By comparing the fermentation parameters, it was found that the mutant S. nodosus ZJB2016050 had an increased ability to absorb nutrients or increased the nutrients allocated to the growth of 


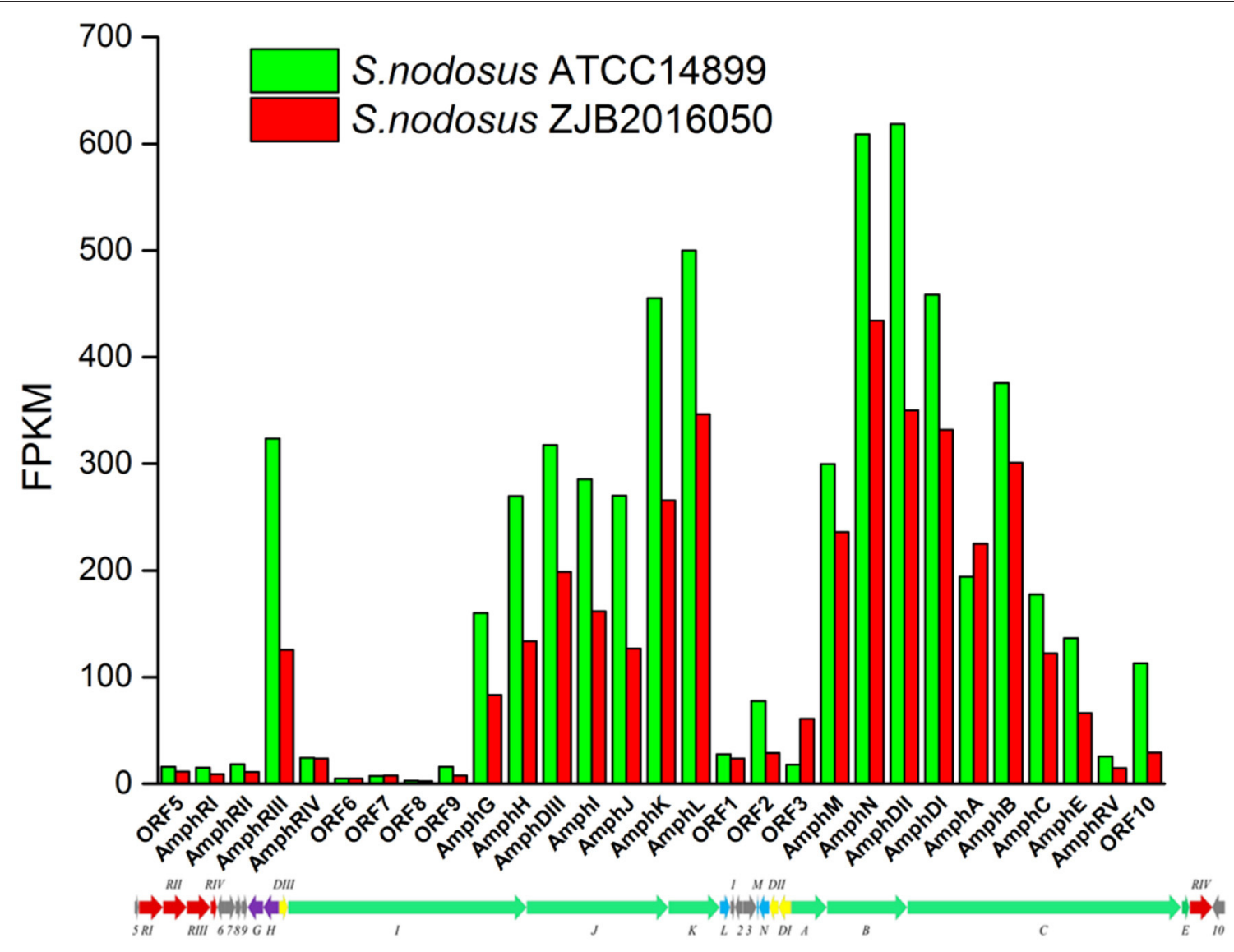

FIGURE 9 | The transcription comparison of the amphotericin biosynthetic gene cluster of S. nodosus. Green bars indicate sample S. nodosus ATCC14899, and red bars indicate sample S. nodosus ZJB2016050. The green arrows represent the core genes of the synthetic gene cluster. The red arrows represent the regulatory factors of the amphotericin synthetic gene cluster. The purple arrows represent transporters of the synthetic gene cluster.

the strain. At the same time, we also speculate that this may be due to dense hyphae or rapid hyphae growth. Even without glass beads, S. nodosus ZJB2016050 will not form pellets in the liquid medium during fermentation, which may help to improve the utilization of nutrients and has special significance for the fermentation of actinomycetes.

By comparative transcriptome analysis, a large number of differences exist in carbohydrate metabolism, which may explain why high-yielding strain used glucose more rapidly. The expression of glucokinase and phosphoglycerate mutase was upregulated and promoted the utilization of glucose. These steps accelerate the consumption of glucose in fermentation. Upregulation of pyruvate dehydrogenase and downregulation of aldehyde dehydrogenase contribute to the accumulation of acetyl-CoA. In addition to being one of the precursors of amphotericin, acetyl-CoA is also an important up-stream precursor of other metabolic pathways. It was speculated that the glucose consumption rate of the mutagenesis $S$. nodosus was faster than that of the wild type, which would accelerate the synthesis of secondary metabolites and make mycelium grow strong. Besides, robust mycelia could accumulate more secondary metabolites.

Expression differences of genes in the TCA cycle play a positive role in the accumulation of succinyl-CoA. With the upregulation of methylmalonyl-CoA mutase and methylmalonyl-CoA epimerase and the downregulation of propionyl-CoA carboxylase, the accumulation of methylmalonyl-CoA as one of the synthesis precursors may be increased. In another study, supplying the precursor methylmalonyl-CoA will help in AmB biosynthesis (Huang et al., 2020).

A type II PKS(PKS5) of sapromomycin analog synthesis gene clusters is downregulated in S. nodosus ZJB2016050. Competing secondary metabolites are more common in Streptomyces. In S. nodosus, the sapromomycin analog will compete with malonyl-CoA, which is the most important synthetic precursor for the synthesis of amphotericin. In another study, amphotericin production increased by knocking out these genes in S. nodosus ZJB2016050 (Huang et al., 2020). 
Type I PKSs of amphotericin synthesis genes were considered as core genes because these genes participate in the carbon skeleton of amphotericin, which is the rate-limiting step in amphotericin synthesis. The AmphA module of the amphotericin synthetic gene cluster synthetizes the first unit using acetylCoA as the precursor (Caffrey et al., 2001). However, a special phenomenon was found in which the expression level of the amphotericin synthesis gene cluster (except for AmphA) in high-yield S. nodosus ZJB2016050 was lower than that of wildtype S. nodosus ATCC14899, and the production of AmB of S. nodosus ZJB2016050 was higher than that of S. nodosus ATCC14899. In a fermentation experiment, we detected the total amount of AmA and $\mathrm{AmB}$ and found that wild-type $S$. nodosus ATCC14899 was higher than S. nodosus ZJB2016050 in the synthesis of amphotericin. The amphotericin skeleton of the wild-type strain preferred flowing to AmA rather than AmB. By comparing the total amount of amphotericin (the sum of $A m A$ and $A m B$ ), we speculate that the total synthesis of amphotericin in wild-type S. nodosus ATCC14899 was more than that of $S$. nodosus ZJB2016050, which is due to the expression difference of the amphotericin synthesis gene cluster. The reason why high-yield strain prefers $A m B$ is because the intracellular reduction $\left(\mathrm{NADPH} / \mathrm{NADP}^{+}\right.$) of $S$. nodosus ZJB2016050 was weaker than that of the wild type, which affected the reduction reaction in the ER5 domain of AmphC. In this study, we analyzed the PPP pathway because we speculated that the synthesis of AmA had an important relationship with intracellular reduction. The decrease in the upstream flow from G6P to glucono-1,5-lactone-6P would affect the whole subsequent step. Even if the 6-phosphogluconate dehydrogenase gene was also upregulated, the overall accumulation of $\mathrm{NADPH}$ may be reduced. In another study, we measured the intracellular reduction $\left(\mathrm{NADPH} / \mathrm{NADP}^{+}\right)$of two strains and found that the high-yield strain had less intracellular reduction than the wild-type strain. The ER5 domain of the AmphC module in amphotericin synthesis consumes NADPH to reduce the $\mathrm{C} 28-\mathrm{C} 29$ of amphotericin and product AmA (Huang et al., 2020).

In past studies on the synthesis of amphotericin B, strategies such as increasing the expression of synthetic gene clusters, knocking out competitive secondary metabolites synthetic gene clusters, and increasing the supply of precursors had been used, while ignoring the biosynthesis of by-product amphotericin A. This study provides new research content for the research on the synthesis of amphotericin by S. nodosus and provides theoretical guidance for subsequent strain transformation.

\section{REFERENCES}

AbuSalah, K. M. (1996). Amphotericin B: an update. Br. J. Biomed. Sci 53, 122-133. Amara, A., Takano, E., and Breitling, R. (2018). Development and validation of an updated computational model of Streptomyces coelicolor primary and secondary metabolism. BMC Genomic 19:519. doi: 10.1186/s12864-0184905-5

Audic, S., and Claverie, J. M. (1997). The significance of digital gene expression profiles. Genome Res. 10, 986-995. doi: 10.1101/gr.7.10.986

\section{CONCLUSIONS}

In summary, a mutated high-yield strain S. nodosus ZJB2016050 was obtained in our lab and had greater advantages in industrial production. By comparative transcriptome analysis, it was found that the expression of glucokinase and phosphoglycerate mutase was upregulated and promoted the utilization of glucose. Upregulation of pyruvate dehydrogenase and downregulation of aldehyde dehydrogenase contribute to the accumulation of acetyl-CoA. The expression differences of genes in the TCA cycle play a positive role in the accumulation of succinyl-CoA. A PKS type II synthesis gene cluster is downregulated in $S$. nodosus ZJB2016050. The total synthesis of amphotericin in wildtype $S$. nodosus ATCC14899 was more than that of S. nodosus ZJB2016050, which is due to the expression difference of the amphotericin synthesis gene cluster. The reason why the highyield strain prefers $\mathrm{AmB}$ is because the intracellular reduction $\left(\mathrm{NADPH} / \mathrm{NADP}^{+}\right.$) of $S$. nodosus ZJB2016050 was weaker than that of the wild type, which affected the reduction reaction in the ER5 domain of AmphC.

\section{DATA AVAILABILITY STATEMENT}

The raw data supporting the conclusions of this article will be made available by the authors, without undue reservation.

\section{AUTHOR CONTRIBUTIONS}

$\mathrm{KH}$ and $\mathrm{BZ}$ conceived and designed the research. $\mathrm{KH}$ and $\mathrm{YC}$ conducted the experiments. Z-QL and Y-GZ contributed reagents or analytical tools. $\mathrm{KH}$ analyzed the data. $\mathrm{KH}$ and Z-QL wrote and modified the manuscript. All authors contributed to the article and approved the submitted version.

\section{FUNDING}

This research was funded by a project from the Department of Education of Zhejiang Province (No. Y201636181) and Zhejiang Provincial Public Welfare Technology Application Research Projects (No. LGF19B060004).

\section{SUPPLEMENTARY MATERIAL}

The Supplementary Material for this article can be found online at: https://www.frontiersin.org/articles/10.3389/fbioe. 2020.621431/full\#supplementary-material

Ausländer, S., Ausländer, D., and Fussenegger, M. (2017). Synthetic biology- the synthesis of biology. Angew. Chem. Int. Ed. 56, 6396-6419. doi: 10.1002/anie.201609229

Baltz, R. H. (2016). Genetic manipulation of secondary metabolite biosynthesis for improved production in Streptomyces and other actinomycetes. J. Ind. Microbiol. Biotechnol. 43, 343-370. doi: 10.1007/s10295-015-1682-x

Bilyk, O., and Luzhetskyy, A. (2016). Metabolic engineering of natural product biosynthesis in actinobacteria. Curr. Opin. Biotechnol. 42, 98-107. doi: $10.1016 /$ j.copbio.2016.03.008 
Brakhage, A. A., and Schroeckh, V. (2011). Fungal secondary metabolites strategies to activate silent gene clusters. Fungal Genet. Biol. 48, 15-22. doi: $10.1016 /$ j.fgb.2010.04.004

Caffrey, P., Lynch, S., Flood, E., Finnan, S., and Oliynyk, M. (2001). Amphotericin biosynthesis in Streptomyces nodosus: deductions from analysis of polyketide synthase and late genes. Chem. Biol. 8, 713-723. doi: 10.1016/S1074-5521(01)00046-1

Cock, P. J. A., Fields, C. J., Goto, N., Heuer, M. L., and Rice, P. M. (2009). The Sanger FASTQ file format for sequences with quality scores, and the solexa/lllumina FASTQ variants. Nucleic Acids Res. 38, 1767-1771. doi: 10.1093/nar/gkp1137

Dufour, A., and Haldenwang, W. G. (1994). Interactions between a Bacillus subtilis anti-sigma factor (RsbW) and its antagonist (RsbV). J. Bacteriol. 176, 1813-1820. doi: 10.1128/JB.176.7.1813-1820.1994

Escandón, P., Chow, N. A., Caceres, D. H., Gade, L., Berkow, E. L., Armsstrong, P., et al. (2019). Molecular epidemiology of candida auris in colombia reveals a highly related, countrywide colonization with regional patterns in amphotericin B resistance. Clin. Infect. Dis. 68, 15-21. doi: 10.1093/cid/ciy411

Feng, W. M., Liang, J. R., Wang, B. B., and Chen, J. H. (2019). Improvement of kojic acid production in Aspergillus oryzae AR-47 mutant strain by combined mutagenesis. Bioproc. Biosyst. Eng. 42, 753-761. doi: 10.1007/s00449-019-02079-9

Flatt, P. M., and Mahmud, T. (2007). Biosynthesis of aminocyclitolaminoglycoside antibiotics and related compounds. Nat. Prod. Rep. 24, 358-392. doi: 10.1039/B603816F

Forsberg, K., Woodworth, K., Walters, M., Berkow, E. L., Jackson, B., Chiller, T., et al. (2019). Candida auris: the recent emergence of a multidrug-resistant fungal pathogen. Med. Mycol. 57, 1-12. doi: 10.1093/mmy/myy054

Hartsel, S., and Bolard, J. (1996). Amphotericin B: new life for an old drug. Trends Pharmacol. Sci 17, 445-449. doi: 10.1016/S0165-6147(96)01012-7

Hopwood, D. A. (2007). Streptomyces in Nature and Medicine: The Antibiotic Makers. Oxford: Oxford University Press. p. 10-6.

Huang, K., Zhang, B., Shen, Z. Y., Cai, X., Liu, Z. Q., and Zheng, Y. G. (2020). Enhanced amphotericin B production by genetically engineered Streptomyces nodosus. Microbiol. Res. 242:126623. doi: 10.1016/j.micres.2020.126623

Jarvis, J. N., Leeme, T. B., Molefi, M., Chofle, A. A., Bidwell, G., Tsholo, K., et al. (2019). Short-course high-dose liposomal amphotericin B for human immunodefciency virus-associated cryptococcal meningitis: a phase 2 randomized controlled trial. Clin. Infect. Dis. 68, 393-401. doi: $10.1093 /$ cid/ciy515

Kieser, T., Bibb, M. J., Buttner, M. J., Chater, K. F., and Hopwood, D. A. (2000). Practical Streptomyces Genetics. Norwich: The John Innes Foundation.

Kim, D., Langmead, B., and Salzberg, S. (2015). HISAT: a fast spliced aligner with low memory requirements. Nat. Methods 12,357-360. doi: 10.1038/nmeth.3317

Kim, M. W., Lee, B. R., You, S. Y., Kim, E. J., Kim, J. N., Song, E., et al. (2018). Transcriptome analysis of wild-type and afs deletion mutant strains identifies synergistic transcriptional regulator of afs $\mathrm{S}$ for a high antibioticproducing strain of Streptomyces coelicolor A3(2). Appl. Microbiol. Biotechnol. 102, 3243-3253. doi: 10.1007/s00253-018-8838-3

Kwak, S., and Jin, Y. S. (2017). Production of fuels and chemicals from xylose by engineered Saccharomyces cerevisiae: a review and perspective. Microb. Cell Fact 16:82. doi: 10.1186/s12934-017-0694-9

Li, J. W., and Vederas, J. C. (2009). Drug discovery and natural products: end of an era or an endless frontier? Science 325, 161-165. doi: 10.1126/science.1168243

Li, R. Q., Li, Y. R., Kristiansen, K., and Wang, J. (2008). SOAP: short oligonucleotide alignment program. Bioinformatics 24, 713-714. doi: 10.1093/bioinformatics/btn025
Liu, H., Marsafari, M., Wang, F., Deng, L., and Xu, P. (2019). Engineering acetyl-CoA metabolic shortcut for eco-friendly production of polyketides triacetic acid lactone in Yarrowia lipolytica. Metab. Eng. 56, 60-68. doi: 10.1016/j.ymben.2019.08.017

McAlister, J. G., and Shapiro, R. S. (2019). New pathogens, new tricks: emerging, frug-resistant fungal pathogens and future prospects for antifungal therapeutics. Ann. N. Y. Acad. Sci. 1435, 57-58. doi: 10.1111/nyas.13739

Medema, M. H., Blin, K., Cimermancic, P., Jager, V., Zakrzewski, P., Fischbach, M. A., et al. (2011). antiSMASH: rapid identification, annotation and analysis of secondary metabolite biosynthesis gene clusters in bacterial and fungal genome sequences. Nucleic Acids Res. 39, 339-346. doi: 10.1093/nar/gkr466

Nami, S., Maleki, A. A., Morovati, H., and Maleki, L. A. (2019). Current antifungal drugs and immunotherapeutic approaches as promising strategies to treatment of fungal diseases. Biomed. Pharmacother. 110, 857-868. doi: 10.1016/j.biopha.2018.12.009

Omata, T., Price, G. D., Badger, M. R., Okamura, M., Gohta, S., and Ohawa, T. (1999). Identification of an ATP-binding cassette transporter involved in bicarbonate uptake in the cyanobacterium Synechococcus sp. strain PCC 7942. Proc. Natl. Acad. Sci. USA. 96, 13571-13576. doi: 10.1073/pnas.96.23. 13571

Parekh, S., Vinci, V. A., and Strobel, R. J. (2000). Improvement of microbial strains and fermentation processes. Appl. Microbiol. Biotechnol. 54, 287-301. doi: $10.1007 / \mathrm{s} 002530000403$

Ta, D. T., and Vickery, L. E. (1992). Cloning, sequencing, and overexpression of a [2Fe-2S] ferredoxin gene from Escherichia coli. J. Biol. Chem. 267, 11120-11125. doi: 10.1016/S0021-9258(19)49883-9

Tam, R., and Saier, M. H. (1993). Structural, functional, and evolutionary relationships among extracellular solute-binding receptors of bacteria. Microbiol. Rev. 57, 320-346. doi: 10.1128/MR.57.2.320-346.1993

Tomii, K., and Kanehisa, M. (1998). A comparative analysis of ABC transporters in complete microbial genomes. Genome Res. 8, 1048-1059. doi: 10.1101/gr.8.10.1048

Wang, Z., Gerstein, M., and Snyder, M. (2009). RNA-Seq: a revolutionary tool for transcriptomics. Nat Rev Genet 10, 57-63. doi: 10.1038/nrg2484

Wanner, B. L. (1993). Gene regulation by phosphate in enteric bacteria. J. Cell Biochem. 51, 47-54. doi: 10.1002/jcb.240510110

Yang, Y. F., Lane, A. N., Ricketts, C. J., Sourbier, C., Wei, M. H., Shuch, B., et al. (2013). Metabolic reprogramming for producing energy and reducing power in fumarate hydratase null cells from hereditary leiomyomatosis renal cell carcinoma. PLOS ONE 8:72179. doi: 10.1371/journal.pone.00 72179

Zhang, B., Zhang, H. D., Zhou, Y. T., Huang, K., Liu, Z. Q., and Zheng, Y. G. (2018). Improvement of amphotericin B production by a newly isolated Streptomyces nodosus mutant. Biotechnol. Appl. Biochem/ 65, 188-194. doi: 10.1002/ba b.1579

Conflict of Interest: The authors declare that the research was conducted in the absence of any commercial or financial relationships that could be construed as a potential conflict of interest.

Copyright (c) 2021 Huang, Zhang, Chen, Liu and Zheng. This is an open-access article distributed under the terms of the Creative Commons Attribution License (CC $B Y)$. The use, distribution or reproduction in other forums is permitted, provided the original author(s) and the copyright owner(s) are credited and that the original publication in this journal is cited, in accordance with accepted academic practice. No use, distribution or reproduction is permitted which does not comply with these terms. 